\title{
Biodesulfurization of the mixture of dibenzothiophene and its alkylated derivatives by Sphingomonas subarctica T7b
}

\author{
Ida Bagus Wayan Gunam ${ }^{1,}$, , Teruo Sone ${ }^{2}$, Kozo Asano $^{2}$ \\ ${ }^{1}$ Department of Agroindustrial Technology, Faculty of Agricultural Technology, Udayana University, Badung, Bali 80361, Indonesia \\ ${ }^{2}$ Research Faculty of Agriculture, Hokkaido University, Kita 9 Nishi 9, Kita-ku, Sapporo, 060-8589, Japan \\ ${ }^{*}$ Corresponding author: ibwgunam@unud.ac.id
}

SUBMITTED 27 December 2020 REVISED 23 June 2021 ACCEPTED 15 July 2021

\begin{abstract}
Organosulfur compounds classified as dibenzothiophenes (DBTs) and their derivatives are contained in petroleum. When used as fuel, these substances release $\mathrm{SO}_{\mathrm{x}}$ emissions, thus contributing to air pollution, acid rain, and climate change. Therefore, it is necessary to reduce the content of these organic sulfur compounds in fuels and one way to achieve this is through bacterial desulfurization. This study reports the biodesulfurization process of a mixture of DBT, 4-hexyl DBT, 4,6-dibutyl DBT, and various organosulfur compounds in light gas oil (LGO). The experiment was conducted by treating $1 \mathrm{~mL}$ of aromatic organosulfur compounds with $100 \mathrm{mg} / \mathrm{L}$ in $n$-tetradecane or $1 \mathrm{~mL}$ LGO with $5 \mathrm{~mL}$ mineral salts in sulfur-free medium, incubated at $27^{\circ} \mathrm{C}$ for 5 days with shaking at $273 \mathrm{rpm}$. Gas chromatography analyses revealed that the growing Sphingomonas subarctica T7b cells desulfurized and converted $88.29 \%$ of DBT to 2 -hydroxybiphenyl as a metabolite while a mixture of DBT and 4,6-dibutyl DBT was desulfurized at $86.40 \%$ and $7.00 \%$, respectively. Furthermore, the mixture of DBT, 4-hexyl DBT, and 4,6-dibutyl DBT had a desulfurization percentage of $84.40 \%, 41.00 \%$, and $6.66 \%$, respectively, after five days of incubation. The compounds were observed to desulfurize slightly better as single compounds compared to when mixed with other aromatic sulfur compounds.
\end{abstract}

KEYWORDS Bacterial desulfurization; aromatic sulfur compounds; 2-hydroxybiphenyl; light gas oil

\section{Introduction}

Petroleum is a crucial non-renewable energy source worldwide, with high demand from numerous industries (Bordoloi et al. 2014; Gunam et al. 2020). However, the combustion process is known to produce hazardous wastes. This includes high sulfur content, which is unfriendly to humans and the environment. These sulfur-oxides $\left(\mathrm{SO}_{\mathrm{x}}\right)$ emissions produce air pollution, acid rain and contribute to climate change (Kobayashi et al. 2001; Gunam et al. 2006; Etemadi et al. 2018). Oldfield et al. (1997) identified atmospheric $\mathrm{SO}_{\mathrm{x}}$ as a major factor in urban environmental air pollution, alongside acid rain, known to play a significant role in forest decline globally.

Light gas oil (LGO) is classified as crude oil and is treated by hydrodesulfurization (HDS). After this process, a few hundred parts per million of sulfur are usually left, and these include dibenzothiophene (DBT), benzothiophene (BT) and their derivatives. According to Zhang et al. (2013), complex alkyl-DBT mixtures in crude oil tend to be altered by individual microbial biodesulfurization. Hence, HDS has been routinely carried out in refineries as an alternative to reduce petroleum sulfur content (Bhatia and Sharma 2010). This process uses metal complex chemical catalysts as well as extremely high temperatures and pressures (Sohrabi et al. 2012; Gunam et al. 2013). However, the procedure is ineffective for the particular polyaromatic sulfur heterocycles (PASHs) present in heavier fractions (Mohebali and Ball 2016). This has mandated further research on biodesulfurization as an alternative technology for a more efficient PASH degradation (Sohrabi et al. 2012; Gunam et al. 2021).

DBT-desulfurizing microorganisms with cleavage activity of C-S bonds are expected to effectively bio-catalyze petroleum biodesulfurization and this reaction uses a ' $4 S$ ' pathway, refers to the four intermediates formed (DBT sulfoxide, DBT sulfone, hydroxyphenyl benzene sulfonate, sulfite), and this pathway occurs through successive oxidation of DBT (Boniek et al. 2015; Yi et al. 2019). Gunam et al. (2006) previously reported that Sphingomonas subarctica T7b is able to desulfurize alkyl DBTs and BTs in this manner.

According to Kobayashi et al. (2001), Chen et al. (2008), and Zhang et al. (2013), DBTs are easily desulfurized by the DBT-desulfurizing bacterium compared to their derivatives (alkyl DBT), including 4-hexyl DBT, 4,6dibutyl DBT, and 4,6-dipentyl DBT. Long alkyl chain 
organosulfur, especially with alkyl substituents, is usually more difficult to desulfurize. Similarly, mixtures with more organosulfur compound types have lower desulfurization rates.

Therefore, this study was carried out to investigate the S. subarctica's T7b biodesulfurization properties on DBT and its derivatives, DBT and 4,6-dibutyl DBT mixture, as well as a DBT, 4,6-dibutyl DBT, and 4-hexyl DBT combination, and to test the strain's ability to desulfurize the various organosulfur compounds present in LGO.

\section{Materials and Methods}

\subsection{Materials}

The reagents used in this experiment include, DBT from Tokyo Kasei Kogyo Co. Ltd., alkyl DBTs from Nard Institute Ltd. (Hyogo, Japan), organic solvent (n-tetradecane) from Wako Pure Chemical Co., Osaka, Japan, and LGO from Petroleum Energy Center, Shizuoka, Japan. All other reagents met analytical standards and therefore did not require further purification before use. Concentrated aromatic compounds fraction (CA) was obtained through commercial LGO fractionation (Gunam et al. 2006).

\subsection{Bacterial strains and culture media}

Sphingomonas subarctica T7b was isolated from soil samples contaminated with oil through enrichment culture, as described by Gunam et al. (2006). Meanwhile, the biodesulfurization evaluations were performed in a mineral salt sulfur-free (MSSF) medium and an organic $n$ tetradecane, with $10 \mathrm{~g} / \mathrm{L}$ glucose as a carbon source, supplemented by $0.54 \mathrm{mM}(100 \mathrm{mg} / \mathrm{L}) \mathrm{DBT}$ as a sole sulfur source. The enrichment culture (MSSF-CA) comprised MSSF, ethanol and CA in the ratio 1000: 2:1 (v/v), while the desulfurization assessment agent (MSSF-TD) contained MSSF medium and n-tetradecane in the ratio 5:1 $(\mathrm{v} / \mathrm{v})$, with various sulfur compounds dissolved in the organic solvent.

\subsection{Seed culture preparation and bio-desulfurization analyses}

For this preparation, fresh $5 \mathrm{~mL}$ of MSSF-CA medium was inoculated with $2 \%(\mathrm{v} / \mathrm{v})$ of mid-log phase of $S$. subarctica T7b preculture and incubated at $27{ }^{\circ} \mathrm{C}$ for $4 \mathrm{~d}$ with 273 stroke-per minute reciprocal shaking. Meanwhile, 6 $\mathrm{mL}$ of the desulfurization assay medium $(5 \mathrm{~mL}$ of MSSF and $1 \mathrm{~mL}$ of TD) was also inoculated with $0.1 \mathrm{~mL}$ of seed culture $\left(\mathrm{OD}_{660}\right.$ of 5$)$ and cultured under similar conditions. Subsequently, the sulfur compound infused n-tetradecane organic layer and the water layer (MSSF medium) were separated through centrifugation at $20,000 \times g$ for $10 \mathrm{~min}$ at $4{ }^{\circ} \mathrm{C}$. This process was repeated for the control samples (un-inoculated medium), as described by Gunam et al. (2006).

\subsection{Analytical procedures}

Bacterial growth and cell concentration were evaluated using water layer $\mathrm{OD}_{660}$ measurements (Gunam et al. 2006), while dibenzothiophene and DBT derivatives were measured through flame photometric detector gas chromatography (GC-FPD). Similarly, the concentrations of these compounds in growth culture were analyzed by GC-14A (Shimadzu, Japan) equipped with a column Zebron ZB-1 (60 $\mathrm{m} \times 0.25 \mathrm{~mm} \times 0.25 \mu \mathrm{m}$; Phenomenex, USA) and an FPD with an initial column oven temperature of 220 ${ }^{\circ} \mathrm{C}$, heated to $280{ }^{\circ} \mathrm{C}$ at a rate of $3{ }^{\circ} \mathrm{C} \mathrm{min}^{-1}$, was utilized. The equipment's injection and detector temperatures were maintained at $300{ }^{\circ} \mathrm{C}$. Subsequently, DBT and derivatives as well as the metabolite 2-hydroxybiphenyl (2-HBP) concentrations were measured with a gas chromatographyflame ionization detector (GC-FID). Meanwhile, the samples were acidified to $\mathrm{pH} 2$ with $6 \mathrm{~N} \mathrm{HCl}$ and extracted with 0.5 volumes of ethyl acetate. An aliquot of this extract was centrifuged and GC-FID (GC-17A, Shimadzu) equipped with a DB-17 column $(0.25 \mathrm{~mm}$ i.d. $\times 30 \mathrm{~m}$ length; J\&W Scientific, Folsom, CA), was used to analyze the supernatant. Helium was utilized as the carrier gas for this analysis and the injector as well as detector temperatures were set at $260{ }^{\circ} \mathrm{C}$. The 2-HBP metabolite was identified with gas chromatography-mass spectrometry (GC-MS-QP5000; Shimadzu), while the organosulfur compound distribution in light gas oil was analyzed by GC-atomic emission detector (GC-AED) (Yu et al. 2006).

\section{Results and Discussion}

\subsection{Growth and desulfurization activity of S. subarc- tica $T 7 b$ in a single substrate}

Figure 1 shows the T7b strain has the ability to grow on MSSF-TD media containing organosulfur compounds and desulfurize DBT, 4,6-dibutyl DBT, and 4-hexyl DBT, respectively at 82.23 ; 8.27 ; and $39.97 \%$ after cultivation at $27{ }^{\circ} \mathrm{C}$ with shaking at $273 \mathrm{rpm}$ for $5 \mathrm{~d}$. DBT compounds

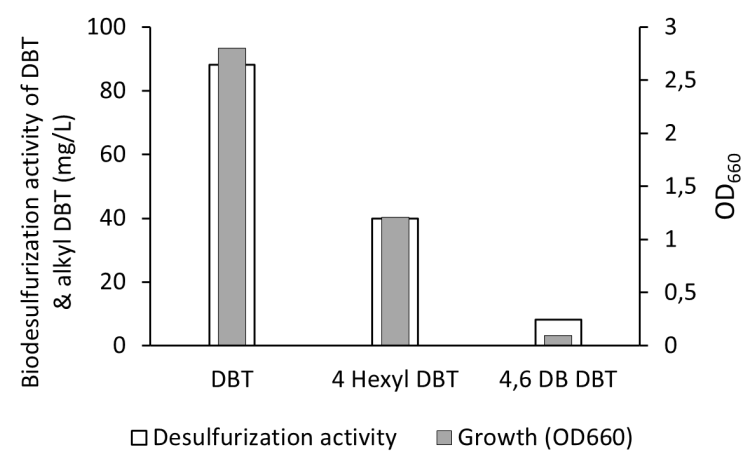

FIGURE $1 S$. subarctica T7b's growth as well as desulfurization activity in MSSF medium and n-tetradecane as a model oil containing the single substrate of DBT and its derivatives $(100 \mathrm{mg} / \mathrm{L})$, incubated at $27^{\circ} \mathrm{C}$, and shaken at $273 \mathrm{rpm}$ for $5 \mathrm{~d}$. 


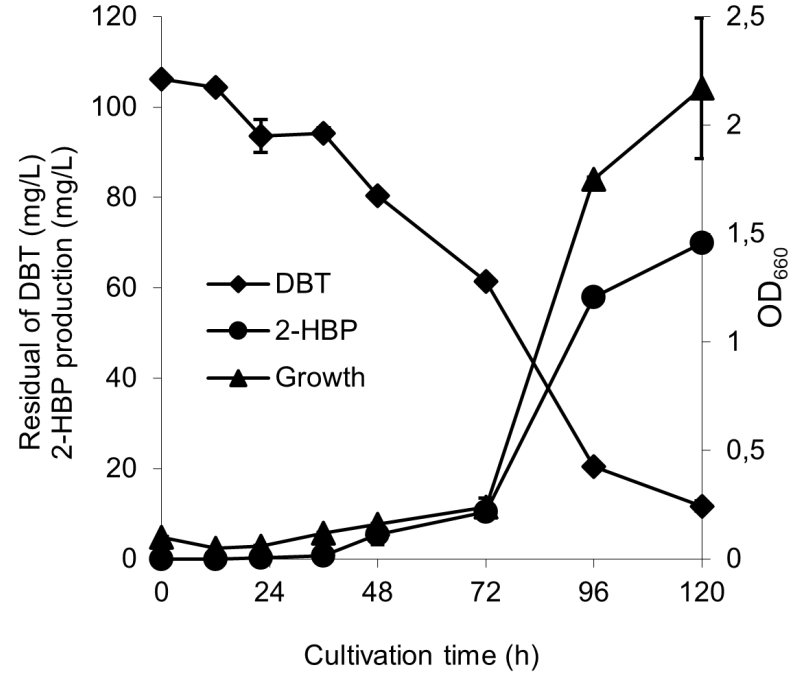

FIGURE 2 Time course of DBT biodesulfurization and 2-HBP production by growing $S$. subarctica T7b cells in MSSF-TD medium.

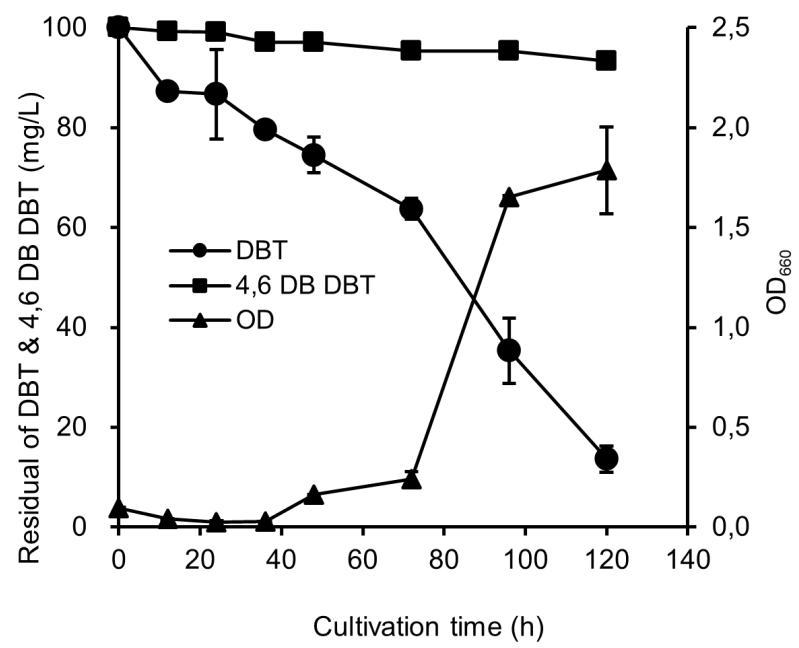

FIGURE 3 Biodesulfurization of DBT and 4,6-dibutyl DBT (1:1) mixture in MSSF-TD medium by growing $S$. subarctica T7b cells.

are therefore much easier to desulfurize and separate compared to the other two derivatives. In addition, the microorganism's cell growth rate was discovered to be directly proportional to the ability to desulfurize the compounds tested.

\subsection{Biodesulfurization of $D B T$ and a mixture of $D B T$ and alkyl DBT}

\subsubsection{Time course of DBT desulfurization}

Figure 2 shows the growth and desulfurization obtained from growing $S$. subarctica T7b cells in MSSF-TD medium with DBT as the sole sulfur source at $27^{\circ} \mathrm{C}$. After 120 h cultivation, the cells of T7b strain $\mathrm{OD}_{660}$ reached 2.17, while the residual DBT and 2-hydroxybiphenyl (the product of the ' $4 \mathrm{~S}$ ' biodesulfurization pathway) concentrations were $14.88 \mathrm{mg} / \mathrm{L}$ (88.29\% desulfurization) and 69.86
mg/L, respectively. The DBT growth and desulfurization patterns exhibited were similar to the previous study counterparts (Gunam et al. 2006). According to GC-MS analysis, this product has the same mass spectrum as authentic 2-HBP, and DBT disappeared from the medium faster than 2-HBP accumulated.

\subsubsection{Time course of mixture of DBT and 4,6-dibutyl DBT}

Figure 3 shows that in a mixture of two organosulfur compounds, the desulfurization of DBT at the beginning of the reaction became relatively slower until day 3 (72 h), but after that the degradation pattern was faster and almost the same as that of a single compound. Finally, DBT can be desulfurized up to $86.00 \%$ on day $5(120 \mathrm{~h})$. While the desulfurization of the compound 4,6-dibutyl DBT from the beginning to the end of incubation was very slow, it could only be desulfurized as much as $7 \%$ on day 5 .

\subsubsection{Time course of a mixture of DBT, 4,6-dibutyl DBT, and 4-hexyl DBT}

Figure 4 shows the mixture of three compounds, with DBT desulfurization occurring at the reaction commencement and becoming relatively slower until the $3^{\text {rd }} \mathrm{d}(72 \mathrm{~h})$. Subsequently, the desulfurization pattern reached almost the same as a single or two compounds mixture, and finally arrives at $86.00 \%$ on day $5(120 \mathrm{~h})$.

In cases where DBT, 4,6-dibutyl DBT, and 4-hexyl DBT are biodesulfurized together, the T7b strain growth patterns observed are slightly different, and a relatively slow growth is exhibited for $2 \mathrm{~d}$, and this only reaches OD660 1.79 after $4 \mathrm{~d}$ of incubation. Figures 2, 3, and 4 show that this desulfurization activity to be a little lower compared to DBT desulfurization with a single compound $\left(\mathrm{OD}_{660}\right.$ 2.17).

The desulfurization pattern was similar, despite the slight decline in DBT desulfurization over a $3 \mathrm{~d}$ period. For instance, in a case where residue from single DBT desulfurization is $61.36 \mathrm{mg} / \mathrm{L}$ or $38.64 \%$ DBT is desulfurize, a DBT and 4,6-dibutyl DBT mixture have a slightly higher residue of $64.0 \mathrm{mg} / \mathrm{L}$ (36.00\% desulfurized). Figure 4 shows that despite a slight reduction in DBT desulfurization, the T7b strain was able to desulfurize 4-hexyl DBT compounds more effectively (41\%) for $120 \mathrm{~d}$. Meanwhile, the desulfurization rate of 4,6-dibutyl DBT in a mixture of three compounds was similar to the desulfurization rate of this compound in a mixture of two compounds was $6.66 \%$, observed after $120 \mathrm{~h}$ incubation at $27^{\circ} \mathrm{C}$ with shaking at $273 \mathrm{rpm}$.

\subsection{Biodesulfurization of light gas oil}

The T7b strain was also tested for LGO organosulfur compounds desulfurization capability through hydrodesulfurization (HDS) treatment with $280 \mathrm{mg} / \mathrm{L}$ sulfur content. LGO contains various aromatic sulfur compounds, including DBT, BT, and derivatives. Also, the T7b strain 


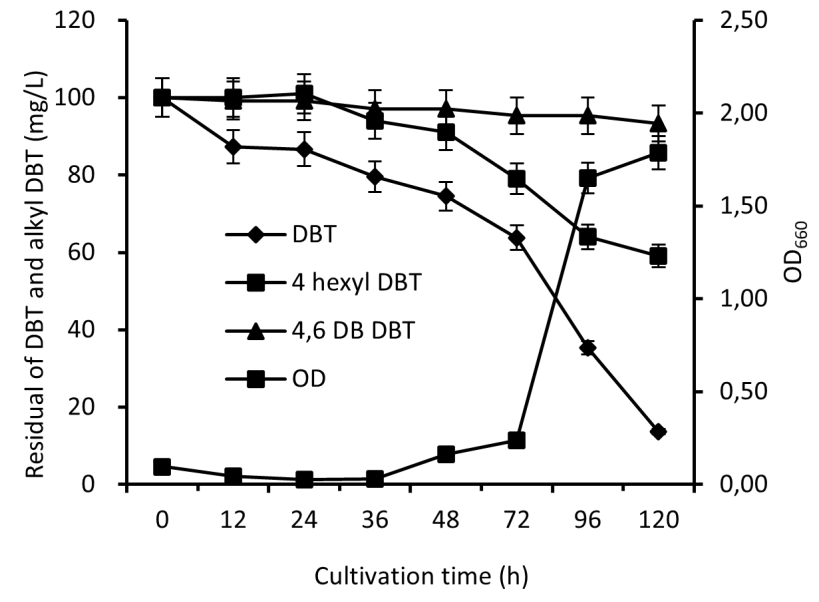

FIGURE 4 Biodesulfurization of a DBT, 4-hexyl DBT, and 4,6dibutyl DBT mixture by growing $S$. subarctica T7b cells in MSSF-TD medium. The data above represents the duplicate sample analyses mean results and the average relative standard deviation for all data points did not surpass $5 \%$.

reduced the total sulfur content of LGO by $116 \mathrm{mg} / \mathrm{L}$ (41.00\%), leaving a residue of $164 \mathrm{mg} / \mathrm{L}$ (59.00\%) within $5.5 \mathrm{~d}$ of incubation in the biphasic batch culture.

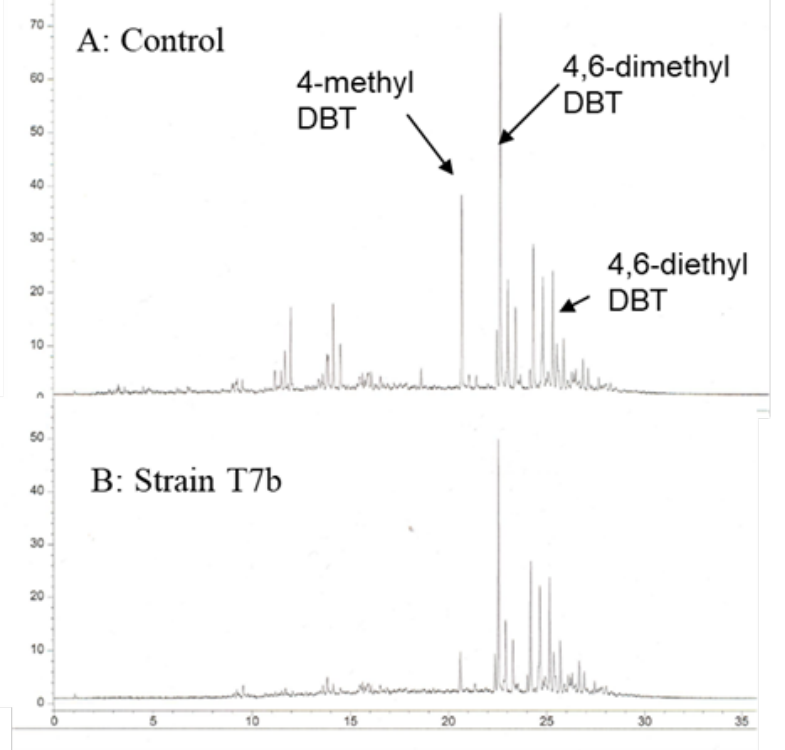

FIGURE 5 LGO GC-AED pattern for the degradation of an organosulfur compound mixture in light gas oil by growing $S$. subarctica T7b cells. A. Commercially hydrodesulfurized LGO (S=280 $\mathrm{mg} / \mathrm{L})$. B. After desulfurization by $\mathrm{S}$. subarctica T7b, (S=164 mg/L). The strain was cultivated aerobically in an MSSF-LGO medium (5 $\mathrm{mL}$ MSSF medium containing $1 \mathrm{~mL}$ of LGO) at $27^{\circ} \mathrm{C}$ with shaking at $273 \mathrm{rpm}$ for $132 \mathrm{~h}$ (5.5 d).

\subsection{Discussion}

This study describes the biodesulfurization and HDS properties exhibited by $S$. subarctica T7b on DBT and its derivatives, as well as LGO. The strain was discovered to effectively desulfurize DBT alone or in the presence of 4,6 dibutyl DBT, a mixture of DBT, 4,6-dibutyl DBT, and 4- hexyl DBT, desulfurize an HDS-treated LGO containing a complex mixture of organosulfur compounds. According to Kobayashi et al. (2001), the alkyl DBTs relative desulfurization activities were reduced compared to all the alkylsubstituent-group carbon atoms. However, each one with a six carbon-alkyl substituent group was not desulfurized.

Figure 2 showed that $100 \mathrm{mg} / \mathrm{L}(0.54 \mathrm{mM})$ DBT was desulfurized within $120 \mathrm{~h}$. Conversely, T7b strain was unable to utilize DBT as the sole carbon source. DBT, 4,6dibutyl DBT, and 4-hexyl DBT were simultaneously removed by $S$. subarctica T7b cells as the sole sulfur source. Chen et al. (2008) reported the simultaneous desulfurization of DBT and 4,6-dimethyl DBT mixture by Mycobacterium sp. ZD-19 tends to occur at a lower activity level compared to cases where the process is carried out separately. This shows that inhibition occurs in the mixture due to substrate competition (Chen et al. 2008). Furthermore, the desulfurization activity was discovered to be influenced by alkyl substituent group types and positions (Kobayashi et al. 2001). Tang et al. (2012) reported that degradation of DBT in the presence of thiophene tends to be influenced by Pseudomonas delafieldii R-8 cells.

These bacteria are able to grow and desulfurize various organosulfur compounds contained in LGO. The results show that the T7b strain is a potential bacterium for LGO aromatic sulfur compounds desulfurization. However, the microorganism's biodegradability is lower in light gas oil compared to the degradation of a single compound or mixtures containing only a few aromatic sulfur compounds types. The apparent substrate competitive inhibition reduced the desulfurization activity exhibited by each alkyl DBT mixture. Furthermore, Zhang et al. (2013) reported that DBT biodesulfurization to be influenced by activity level and alkyl DBT presence in the reaction mixture. This phenomenon was also observed in LGO biodesulfurization due to the alkyl-DBT and BT complex mixtures present (Kobayashi et al. 2001). In the shorter cultivation time, the LGO aromatic sulfur T7b desulfurization percentage was discovered to be $41 \%$ after incubation for $5.5 \mathrm{~d}$. This result is lower compared to the $71.42 \%$ attained after culturing for $7 \mathrm{~d}$ with $P$. agglomerans D23W3, as reported by Bhatia and Bhatia and Sharma (2010). In addition, Rhodococcus sp. IMP-S02 is able to remove around $60 \%$ of the crude oil's organosulfur from crude oil after incubation at $30{ }^{\circ} \mathrm{C}$ for $7 \mathrm{~d}$ (Castorena et al. 2002). The MG1 consortium and Rhodococcus strain IGTS8 reduced the sulfur content of diesel oil by $25 \%$ for $7 \mathrm{~d}$ of incubation (Awadh et al. 2020).

\section{Conclusions}

T7b strain cells successfully desulfurized and converted $88.29 \%$ of DBT to a 2-HBP metabolite. Meanwhile, for DBT and 4,6-dibutyl DBT combination, the desulfurization percentages were $86.40 \%$ and $7.00 \%$, respectively and the DBT, 4-hexyl DBT, and 4,6-dibutyl DBT mixture were respectively desulfurized in $84.40 \%$, $41.00 \%$, and $6.66 \%$ percentages for $5 \mathrm{~d}$ incubation. Furthermore, the desulfurization rate of a DBT compound is slightly higher com- 
pared to when mixed with other aromatic organosulfur compounds. T7b strain also desulfurized $41 \%$ of aromatic sulfur compounds in LGO for $5.5 \mathrm{~d}$ at $27^{\circ} \mathrm{C}$ with reciprocal agitation at $273 \mathrm{rpm}$.

\section{Acknowledgments}

The authors are thankful for the financial support from the TPSDP Project, Indonesia (ADB Loan No 1792-INO) grants. The author also thanks to the committee of the 5th International Conference on Climate Change 2021 for valuable discussion.

\section{Authors' contributions}

IBWG, TS, and KA designed the study and documented the manuscript. IBWG carried out the laboratory experiments as well as data analyses, while the final manuscript version was read and approved by all authors.

\section{Competing interests}

The author declare that they have no competing interest.

\section{References}

Awadh M, Mahmoud H, Abed RM, El Nayal AM, Abotalib N, Ismail W. 2020. Diesel-born organosulfur compounds stimulate community re-structuring in a diesel-biodesulfurizing consortium. Biotechnol Rep. 28. doi:10.1016/j.btre.2020.e00572.

Bhatia S, Sharma DK. 2010. Biodesulfurization of dibenzothiophene, its alkylated derivatives and crude oil by a newly isolated strain Pantoea agglomerans D23W3. Biochem Eng J. 50(3):104-109. doi:10.1016/j.bej.2010.04.001.

Boniek D, Figueiredo D, Dos Santos AFB, De Resende Stoianoff MA. 2015. Biodesulfurization: A mini review about the immediate search for the future technology. Clean Technol Environ Policy. 17(1):29-37. doi:10.1007/s10098-014-0812-X.

Bordoloi NK, Rai SK, Chaudhuri MK, Mukherjee AK. 2014. Deep-desulfurization of dibenzothiophene and its derivatives present in diesel oil by a newly isolated bacterium Achromobacter sp. to reduce the environmental pollution from fossil fuel combustion. Fuel Process Technol. 119:236-244. doi:10.1016/j.fuproc.2013.10.014.

Castorena G, Suárez C, Valdez I, Amador G, Fernández L, Le Borgne S. 2002. Sulfur-selective desulfurization of dibenzothiophene and diesel oil by newly isolated Rhodococcus sp. strains. FEMS Microbiol Lett. 215(1):157-161. doi:10.1016/S03781097(02)00922-9.

Chen H, Zhang WJ, Chen JM, Cai YB, Li W. 2008. Desulfurization of various organic sulfur compounds and the mixture of DBT + 4,6-DMDBT by Mycobacterium sp. ZD-19. Bioresour Technol. 99(9):3630 3634. doi:10.1016/j.biortech.2007.07.034.

Etemadi N, Sepahy AA, Mohebali G, Yazdian F, Omidi M. 2018. Enhancement of bio-desulfurization capability of a newly isolated thermophilic bacterium using starch/iron nanoparticles in a controlled system. Int J Biol Macromol. 120:1801-1809. doi:10.1016/j.ijbiomac.2018.09.110.

Gunam IB, Setiyo Y, Antara NS, Wijaya IM, Arnata IW, Putra IW. 2020. Enhanced delignification of corn straw with alkaline pretreatment at mild temperature. Rasayan J Chem. 13(2):1022-1029. doi:10.31788/RJC.2020.1325573.

Gunam IBW, Sitepu A, Antara NS, Triani IGAL, Arnata IW, Setiyo Y. 2021. Bacterial desulfurization of dibenzothiophene by pseudomonas sp. Strain kwn5 immobilized in alginate beads. Jurnal Teknologi. 83(2):107-115. doi:10.11113/jurnalteknologi.v83.15080.

Gunam IBW, Yaku Y, Hirano M, Yamamura K, Tomita F, Sone T, Asano K. 2006. Biodesulfurization of alkylated forms of dibenzothiophene and benzothiophene by Sphingomonas subarctica T7b. J Biosci Bioeng. 101(4):322-327. doi:10.1263/jbb.101.322.

Gunam IBW, Yamamura K, Nengah Sujaya I, Antara NS, Aryanta WR, Tanaka M, Tomita F, Sone T, Asano K. 2013. Biodesulfurization of dibenzothiophene and its derivatives using resting and immobilized cells of Sphingomonas subarctica T7b. J Microbiol Biotechnol. 23(4):473-482. doi:10.4014/jmb.1207.07070.

Kobayashi M, Horiuchi K, Yoshikawa O, Hirasawa K, Ishii Y, Fujino K, Sugiyama H, Maruhashi K. 2001. Kinetic analysis of microbial desulfurization of model and light gas oils containing multiple alkyl dibenzothiophenes. Biosci, Biotechnol, Biochem. 65(2):298304. doi:10.1271/bbb.65.298.

Mohebali G, Ball AS. 2016. Biodesulfurization of diesel fuels - Past, present and future perspectives. Int Biodeterior Biodegrad. 110:163-180. doi:10.1016/j.ibiod.2016.03.011.

Oldfield C, Pogrebinsky O, Simmonds J, Olson ES, Kulpa CF. 1997. Elucidation of the metabolic pathway for dibenzothiophene desulphurization by Rhodococcus sp. strain IGTS8 (ATCC 53968). Microbiology. 143(9):2961-2973. doi:10.1099/00221287-1439-2961.

Sohrabi M, Kamyab H, Janalizadeh N, Huyop FZ. 2012. Bacterial desulfurization of organic sulfur compounds exist in fossil fuels. J Pure Appl Microbiol. 6(2):717729.

Tang H, Li Q, Wang Z, Yan D, Xing J. 2012. Simultaneous removal of thiophene and dibenzothiophene by immobilized Pseudomonas delafieldii R-8 cells. Chin J Chem Eng. 20(1):47-51. doi:10.1016/S10049541(12)60362-0.

Yi Z, Ma X, Song J, Yang X, Tang Q. 2019. Investigations in enhancement biodesulfuriza- 
tion of model compounds by ultrasound preoxidation. Ultrason Sonochem. 54:110-120. doi:10.1016/j.ultsonch.2019.02.009.

Yu B, Ma C, Zhou W, Wang Y, Cai X, Tao F, Zhang Q, Tong M, Qu J, Xu P. 2006. Microbial desulfurization of gasoline by free whole-cells of Rhodococcus erythropolis XP. FEMS Microbiol Lett. 258(2):284-289. doi:10.1111/j.1574-6968.2006.00227.x.

Zhang SH, Chen H, Li W. 2013. Kinetic analysis of biodesulfurization of model oil containing multiple alkyl dibenzothiophenes. Appl Microbiol Biotechnol. 97(5):2193-2200. doi:10.1007/s00253-012-4048-6. 